\title{
Editorial on the Impact of the "International Training Guidelines for Endovascular Stroke Intervention" on Training and Education in Germany
}

\author{
A. Berlis ${ }^{1}$
}

Published online: 29 February 2016

C Springer-Verlag Berlin Heidelberg 2016

Stroke and its successful endovascular treatment has changed the world. It is a fact that ischemic stroke is a leading cause of death and disability worldwide. Until 2014, intravenous tissue plasminogen activator (t-PA) was the only proven treatment for acute ischemic stroke. The turning point was 2015 with the publication of five well-known randomized, multicenter prospective trials that provided Class 1, Level A evidence in the support of endovascular thrombectomy. These results have led to guideline recommendations advocating endovascular treatment in addition to t-PA for patients with emergent large vessel occlusion (ELVO) and as first-line therapy for patients who are not eligible for intravenous thrombolysis.

What followed can be considered stroke mania. Is this the end of the success story that started 35 years ago? No. It is time to define the rules and evaluate the current situation.

It is amazing that in March 2016 an international multisociety consensus document will be published and the leading societies all over the world have found a consensus statement for international training guidelines for endovascular stroke intervention. The guidelines for stroke thrombectomy will be simultaneously published in JNIS, INR, and other journals in March 2016. The following societies are contributors: AANS/CNS; ASNR; AAFITN; CCINR; ANZSNR; ANZAM, NSA, CING, ESMINT, ESNR, JSNET, SILAN, SNIS, SVIN, and WFITN. The mammoth project of formulating a worldwide standard was implemented in a remarkably short time, thus, showing the importance of this therapy.

\footnotetext{
A. Berlis

ansgar.berlis@klinikum-augsburg.de
}

Chefarzt Diagnostische und Interventionelle Neuroradiologie, Klinikum Augsburg, Stenglinstr. 2, 86156 Augsburg, Germany
There are many questions to answer: Do we have enough specialists who can perform this therapy? Who should perform the therapy? Is it better for an inexperienced physician do treatment or lose precious time by going long distances? How do we define international standards for training and education?

The Guidelines Present Answers, Here an Excerpt from the Publication A multidisciplinary British Intercollegiate Stroke Working Party put forth a document outlining the safe delivery of mechanical thrombectomy, which highlights that operators should not normally carry out procedures with which they are unfamiliar and that they should recognize ad-hoc arrangements are not in the best interest of patients. Catheter skills are mandatory, but (first part added by the author) catheter skills from other circulations do not replace the need for formal training in safe intracranial microcatheter navigation, device placement, and adequate management of complications.

The world is diverse and endovascular stroke treatment is performed by different physicians in different countries. Prerequisite is that there is a long experience with acute ischemic stroke, which is a complex disease. Successful endovascular treatment is based on the comprehensive ability to rapidly integrate patient history, severity of the disease, dedicated interpretation of brain images, resulting in a treatment plan. Both patient selection and procedural expertise are critical to achieve a good clinical outcome.

Summary of the Guidelines The baseline training and qualification include residency training (in radiology, neurology, or neurosurgery) which should include documented training in the diagnosis and management of acute stroke, the interpretation of cerebral angiography and neuroimaging under the supervision of a board-certified neuroradiologist, 
neurologist, or neurosurgeon with subsequent board eligibility or certification. The residency program and supervising physicians should be accredited according to the national standards as they pertain to the countries involved.

Dedicated training in Interventional Neuroradiology under the direction of a Neurointerventionalist (with neuroradiology, neurology, or neurosurgical training background), at a high-volume center. It is preferred that this is a dedicated year, which occurs after graduating from residency (i.e., a fellowship). A training program accredited by a national accrediting body is also strongly preferred but not required. Published standards exist for various countries.

Outcomes should be tracked and recorded. While threshold levels for recanalization, complication rates, etc. have yet to be established, we suggest the following as a minimum: successful recanalization (modified TICI $2 b$ or 3 ) in at least $60 \%$ of cases, embolization to new territory of less than $15 \%$. Symptomatic intracranial hemorrhage (i.e., parenchymal hematoma on imaging with clinical deterioration) rate less than $10 \%$.

It is vital that the physician have ongoing stroke specific continuing medical education. A minimum of $16 \mathrm{~h}$ of stroke specific education every 2 years is suggested. Individual physician outcomes should conform to national standards and institutional requirements. In addition, the physician should participate in an ongoing quality assurance and improvement program.

\section{Impact on the German Curriculum for Endovascular Stroke Treatment}

Fortunately, a training concept for endovascular stroke treatment that complies with the international training guidelines in many respects was started in 2012. The DeGIR/DGNR concept is structured training with three levels of certification: level 1-basic qualification in interventional radiology (IR); level 2-specialized training in interventional radiology (IR) and interventional neuroradiology (INR); and level 3 - qualification as a teaching and training institution. The DeGIR/DGNR concept aims to qualify interventional radiologists and interventional neuroradiologists by structuring the training of interventional procedures to guarantee indepth knowledge and broad skills that are required in clinical practice. The conditions to obtain the "Stroke" Module E of level 2 require participation in DeGIR/DGNR-certified courses with the achievement of $30 \mathrm{CME}$ points per module. Module E could be reached by radiologists as well as neuroradiologists with certification of at least 100 independently performed treatments in Module E with at least 30 intracranial and at least 30 extracranial procedures. After completing the requirements for Module E, oral and written tests are required for accreditation.

The German endovascular stroke treatment concept is closely linked with the stroke unit concept of the German Stroke and Neurological Societies (DSG and DGN). We are present in all 107 German transregional stroke units $(85 \%$ neuroradiological and $15 \%$ radiological interventionalists). In fact, it is possible to treat endovascular stroke $24 \mathrm{~h} /$ day and 7 days/week in 127 hospitals in Germany. Since December 31, 2015, we have 184 accredited Module E interventionalists, while approximately 150 applications are still being processed.

Differences to the International Guidelines Our institutions participate in the DeGIR QS documentation and the following data are also analyzed: successful recanalization, embolization to new territory, and symptomatic intracranial hemorrhage. First of all, we did not define a critical level for this parameter. Second, these data could be personalized but in most of the cases the data will be analyzed per institution.

Of interest is that a minimum of $16 \mathrm{~h}$ of stroke specific education every 2 years is suggested. Actually, we did not define a timely prescribed mandatory training event. In Germany, state-certified specialized training every 5 years is mandatory and we have to sample credit points. Further engagement should be avoided and, of course, additional specific neurointerventional training should be part of the mandatory training.

The DeGIR QS documentation is successful. In 2014, we registered 2967 recanalization treatments and in 2015 the amazing number of 7088 cases (date February 15, 2016 and the register is closed for 2015 on February 29, 2016). These data are incredible and excellent, but we strive to improve the data quality and to implement follow-up data. It is an ongoing process and we still need improvements. But it is more than a first step and for the future we should think about international data documentation. In fact, the DeGIR QS documentation is already used by interventionalists in Austria, Germany, Switzerland, and one German colleague from Tasmania.

The international guidelines for training and education are a very important step to standardize stroke treatment worldwide. Our training and education program is broadly consistent with the international training guidelines. We have a short history of 2 years assist and another 4 years working with training, education, and quality assurance in interventional neuroradiology (Module $\mathrm{E}$ for recanalization as well as Module F for embolization). It is a successful story and we can be proud to have anticipated the necessity 6 years ago. 
Acknowledgments American Academy of Neurological Surgeons/ Congress of Neurological Surgeons (AANS/CNS): S. Lavine, American Society of Neuroradiology (ASNR): H. Rowley Asian Australasian Federation of Interventional and Therapeutic Neuroradiology (AAFITN): W. Chong

Australian and New Zealand Society of Neuroradiology - Conjoint Committee for Recognition of Training in Interventional Neuroradiology (CCINR) representing the RANZCR (ANZSNR), ANZAN and NSA: H. Rice

Canadian Interventional Neuro Group (CING): C. O'Kelly European Society of Neuroradiology (ESNR): O. Jansen, M. Muto European Society of Minimally Invasive Neurologic Therapy (ESMINT): I. Szikora

Japanese Society for Neuroendovascular therapy (JSNET): N. Sakai
Sociedad Ibero Latino Americana de Neuroradiologica (SILAN): O. Diaz, P. Lylyk

Society of NeuroInterventional Surgery (SNIS): M. V. Jayaraman, A. Patsalides, C. D. Gandhi, S. K. Lee, T. Abruzzo, B. Albani, S. A. Ansari, A. S. Arthur, B. W. Baxter, K. R. Bulsara, M. Chen, J. E. Delgado-Almandoz, J. F. Fraser, D. V. Heck, S. W. Hetts, J. A. Hirsch, M. S. Hussain, R. P. Klucznik, W. J. Mack, R. A. McTaggart, P. M. Meyers, J. Mocco, C. J. Prestigiacomo, G. L. Pride, P. A. Rasmussen, R. M. Starke, P. J. Sunenshine, R. W. Tarr, D. F. Frei

Society of Vascular and Interventional Neurology (SVIN): M. Ribo, R. G. Nogeuira, O. O. Zaidat

World Federation of Interventional and Therapeutic Neuroradiology (WFITN): S. Pongpech, G. Rodesch, M. Soderman, K. ter Brugge, A. Taylor, T. Krings 